\title{
CONQUERIDORS DEL SECÀ: EL PROCÉS DE FUNDACIÓ DE LES PRIMERES SOCIETATS CIVILS DE REG A LA PLANA DE CASTELLÓ (1897-1914)
}

\section{DRY LAND CONQUERORS: THE FOUNDING PROCESS OF THE FIRST CIVIL IRRIGATION SOCIETIES IN LA PLANA DE CASTELLÓN (1897-1914)}

\author{
Cristian Pardo Nacher \\ Universitat de València
}

\begin{abstract}
RESUM
L'objecte d'estudi d'aquest article és conèixer el procés de fundació i constitució de gran part de les primeres societats de reg a la Plana de Castelló, amb la intenció de presentar aquest fenomen com una nova font d'estudi per a conèixer amb més precisió les motivacions generadores de la transformació dels antics secans en noves terres de regadiu, aptes per al cultiu de la taronja, a principis del segle XX. Una transformació efectuada, com veurem, gràcies a l'associacionisme entre un grup heterogeni d'individus amb interessos comuns, i a l'aplicació per primera vegada de la maquinaria industrial al camp, mitjançant l'ús de motors a vapor als pous.
\end{abstract}

Paraules clau: Expansió regadiu. Expansió taronja. Associacionisme agrari. Societats de reg. Industrialització.

\section{ABSTRACT}

This article intends to reveal the process by which most of the first irrigation societies in la Plana de Castelló were founded and constituted. The aim is to introduce this phenomenon as a new source of study to gain a deeper knowledge of the reasons behind the transformation of former dry lands into new irrigation lands suitable for orange growing at the beginning of the $20^{\text {th }}$ century. As we shall see, this agrarian transformation was the result of the union of different kinds of landowners with common economic interests and the first use of industrial machinery in the countryside through the use of steam engines for building wells.

Keywords: Irrigated land expansion, orange tree expansion, irrigation societies, Valencian industrialisation. 


\section{Introducció}

La Plana de Castelló, i més concretament el terme rural de Vila-real, és l'escenari per excel.lència on situar l'estudi de l'expansió del cultiu de la taronja més enllà de les tradicionals àrees de regadiu', ja que fou aquesta zona del País Valencià, la primera en originar la peculiar fórmula de les societats civils de reg. Fórmula què, com veurem, és aquella on un grup $d^{\prime}$ individus creen una societat o conveni per a construir un pou (o sènia) de gran profunditat amb la intenció d'extraure una capacitat suficient d'aigua com per a poder convertir una determinada àrea "associada" de secà, en regadiu i així beneficiar-se a mitjà termini amb els beneficis del tarongerar.

Una volta definit el procés, cal advertir que per al nostre enteniment, aquest fenomen ha sigut poc tractat per la historiografia agrària valenciana. L'estudi de les societats de reg ha estat fins ara relegat a un segon plànol acadèmic, on ningú mai ha dubtat de la seva importància, però on al mateix temps, s'han tractat únicament com a un factor més de transformació de l'ús de la superfície agrària, quan en realitat representen una experiència molt més complexa i plena de possibilitats d'estudi.

I és què, la fundació de sènies té una cronologia molt ampla, de quasi 75 anys. Motiu pel qual, el seu estudi és un veritable reflex de l'evolució de l'economia i la societat valenciana durant el segle XX. Aquesta evolució ve marcada per una etapa inicial a partir de 1897, on es realitzaran els primers intents associatius que aniran consolidant-se durant tota la dècada de 1900, fins a l'arribada de la Gran Guerra (1914). Aquest conflicte internacional alterarà la demanda exterior de la taronja negativament i paralitzarà tot el procés durant quasi un decenni. No serà fins a la dècada de 1920 quan tornaren a haver-hi noves fundacions, que tot $\mathrm{i}$ ser menys nombroses que les anteriors, es prolongaran, coincidint amb l'època daurada de l'exportació de taronja valenciana, fins a 1932. A partir d'aquesta data, la creació de societats de reg passarà a ser de caràcter esporàdic i aïllat durant més de trenta anys, situació no sols marcada per la postguerra i les

1 Aquelles àrees de Vila-real, Borriana, Almassora, Nules i Castelló que són regades per l'aigua procedent del riu Millars mitjançant assuts i sèquies, moltes d'elles traçades des del segle XIII. 
gelades, sinó també per la transformació, ja quasi finalitzada, del secà en regadiu que fa menys necessària la construcció de nous pous.

\section{GRÀFIC 1}

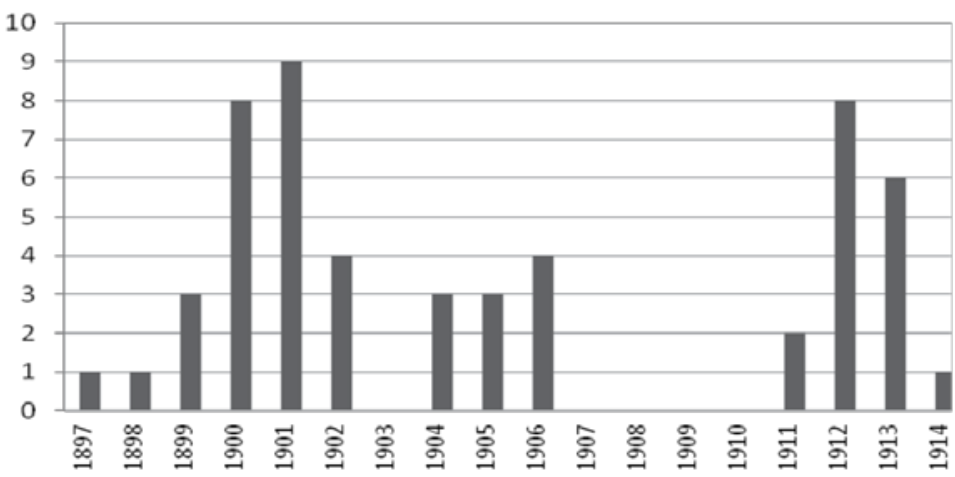

Fundació de les societats de reg estudiades (1897-1914)

Aquesta prolongada evolució, perfectament podria suposar un objecte d'estudi per si mateix, ja que analitzant a fons tots els factors econòmics, politics i socials que marcaren la creació de noves societats, es veurien clarament els ritmes de transformació agrària. Però, en aquest cas, malgrat la importància d'aquest fet, ens centrarem únicament en el primer període (1897-1914), ja que si analitzarem les dades de totes les societats constituïdes al llarg del segle XX ens tocaria barrejar distints contextos històrics i distintes generacions $d^{\prime}$ 'individus. Preferim doncs, si aquest és un treball amb intenció introductòria, començar pel principi, i apropar-nos a les motivacions i als protagonistes originals, sense cap tipus de contaminació contextual posterior.

Aquest treball tindrà per tant, l'objectiu de conèixer de forma més acurada quines foren les motivacions que provocaren la fundació de les primeres societats de reg, així com la transformació del secà, i com no, l'expansió del tarongerar. De la mateixa manera què també intentarem aproximar-nos més a la figura dels fundadors d'aquesta primera generació de sènies, per cercar els seves interessos, les seves aspiracions, la seva mentalitat...

Pel que fa a les eines de treball, per a dur a terme la recerca d'informació hem utilitzat principalment les escriptures fundacionals de les mencionades sènies, que corresponen a diversos notaris de Vila-real i d'Almassora. 
Aquesta documentació ha sigut consultada en diferents arxius com ara: I'Associació Comarcal de Pous de Reg (A.C.P.R.), situada a Vila-real, i indispensable per a la realització d'aquest treball'; I'Arxiu Històric Provincial de Castelló (A.H.P.), molt útil per a completar l'anterior, encara que a dia de hui tan sols hi ha protocols notarials fins a 1904; i finalment, el fons "Associacions de reg" situat a l'Arxiu Municipal de Vila-real (A.M.Vr.), recentment inventariat i catalogat per l'autor d'aquest mateix article. Aquest fons destaca per tindre una important varietat de documents administratius que ens ajuden a reconstruir el funcionament intern d'una sènia dia a dia $^{3}$.

Tot $\mathrm{i}$ la nombrosa documentació consultada, existeixen alguns problemes que s'ha de tindre en compte al llarg de la lectura d'aquest estudi, i és que no s'han conservat totes les escriptures fundacionals d'aquest període. No obstant, hem intentat que el percentatge de sènies consultades fora el més elevat possible, amb la intenció d'aproximar-nos el màxim a la realitat. En el cas de Vila-real, fins a 1914 disposem de trenta-nou escriptures diferents (quasi un $80 \%$ del total), cinc en el cas d'Almassora, tres en el de Castelló $\mathrm{i}$ una en el de Borriana. Per altra banda cal assenyalar, que per aquest estudi no sols utilitzarem els pous coneguts sinó també projectes frustrats que no arribaren a materialitzar-se.

Finalment, cal assenyalar que aquest treball utilitzarà sempre les mides de superfície valencianes de l'època, així que serà habitual parlar de fanecades (fa) què són equivalents a $831,08 \mathrm{~m}^{2}$, corresponent a la dotzena part d'una hectàrea (Ha). Així com la braça, equivalent a 4,15 m², sent 200 braces una fanecada.

\section{UN REGADIU FINIT: L'ORIGEN DE LES SOCIETATS DE REG}

Abans de començar a parlar del procés fundacional de les primeres societats de reg, cal fer menció dels factors que les feren possible. En aquest punt, desenvoluparem l'explicació més tradicional, que no és més que la sènia com a conseqüència de l'expansió del tarongerar. Una visió que utilitzarem únicament com a punt de partida, ja que al llarg d'aquest treball tractarà de ser matisada.

Dit açò, per a entendre eixa expansió cítrica hem de remuntar-nos a l'origen del cultiu de la taronja de la Plana com a producte comercial.

2 Aprofitem per a agrair l'amabilitat del president d'aquesta associació Manuel Colonques, i del secretari Miguel Llopico.

3 Igualment destacable es l'amabilitat dels funcionaris d'aquest arxiu i del seu director Vicent Gil Vicent. 
D'aquesta manera, sembla que, el primer hort de tarongers amb intencions comercials estigué a Vila-real l'any $1816^{4}$, tot i que no seria fins a les dècades de 1840 i 1850 quan el seu cultiu es faria veritablement significatiu. Aquesta transformació, limitada en principi a les terres regades directament pel riu Millars, es veuria paralitzada a la dècada de 1860 a causa de la plaga de la goma. Una volta superada, als anys setanta, es reprendria amb molta més força, començant a convertir-se en un autèntic monocultiu a I'horta tradicional.

Segons les teories clàssiques d'autors com Bono o $\mathrm{Abad}^{5}$, aquesta expansió s'originà com a conseqüència de l'estímul produït per l'augment de la demanda internacional. Amb aquest creixent mercat, els beneficis a l'alça d'aquest fruit foren del tot irresistibles per als propietaris, de manera que començà un veritable desenvolupant industrial, que modificaria per a sempre el model econòmic. Per altra banda, unida a aquestes raons, cal tindre en compte altres factors que afavoriren l'expansió de la taronja com ara: els avantatges de reg respecte als cultius de secà, els incentius fiscals, la decadència dels cultius tradicionals i la introducció del guano com a adob (Garrido, S., 2004: 82-90).

Dit açò, cap a l'any 1882 la superfície de regadiu ocupada per tarongers estava al $63,6 \%$, i tan sols divuit anys després superaria el $80 \%$ de la seua capacitat. No obstant, malgrat aquesta ràpida expansió, no hem d'oblidar que la superfície de regadiu a la Plana era finita. D'aquesta manera a Vila-real tan sols es podien transformar unes 30.000 fanecades i per tant, calia buscar alternatives per a que aquesta superfície poguera incrementar-se.

La opció més lògica era mirar cap al riu Millars, principal subministrador d'aigua a les hortes de la Plana, però aquest riu degut al seu caràcter mediterrani disposava de importants variacions de cabal i forts estivatges. Açò generà als mesos d'estiu caresties d'aigua que generaren tensions entre llauradors i pèrdues de part de les collites ${ }^{6}$. Motiu pel qual, per a evitar-ho, les comunitats de regants posaven obstacles a l'ampliació de les hortes, ja que per a determinar la seua superfície no es basaven en la quantitat d'aigua

4 MARTÍ, P. (1895).

5 ABAD, V. (1984) i BONO, E. (2010).

6 GARRIDO, S. (2010: 80). Aquest autor calculà que la necessitat d'aigua a l'horta de Vila-real a l'agost de 1812 era de 1.1770 hm² $^{2}$ i destacà que aplicant aquest criteri a la disponibilitat d'aigua en anys posteriors, entre 1912 i 1930 hi hagueren sis anys on l'aigua del riu seria insuficient durant aquest més per a regar l'horta. 
que podia dur el riv', sinó més bé, en la quantitat d'aigua que duria aquest en situacions d'escassetat (Garrido, S., 2010: 78-80).

D'aquesta manera, si l'ampliació de l'àrea de regadiu no es podia efectuar amb l'ajuda del riu, no quedava altra opció que extraure-la del subsòl mitjançant la construcció de pous. El problema estava en que l'aigua s'encontrava a una profunditat mitjana de seixanta metres, i per tant el cost de la perforació i de la maquinaria industrial necessària per a elevar les aigües era molt elevat. Motiu pel qual els primers pous de la zona estaven fets per gent adinerada com Carlos Shartou a l'any 1876, José Ramón Latorre o Vicente Amorós (Traver García, B., 1935: 103), coincidint cronològicament amb l'accentuació de les noves plantacions de tarongerar. Així doncs, la necessitat de costejar aquesta despesa de forma collectiva fou un factor important per a la creació de societats de reg, però no fou l'únic motiu. $\mathrm{Hi}$ ha que tindre en compte que la Plana es caracteritzava pel minifundi i per la escassa concentració de la terra. Aquest aspecte incrementa la necessitat associativa, ja que encara que un individu tingués per ell mateix el suficient "capital" com per a poder construir un pou individual, no li era rentable ferho tot sol per a una petita porció de terra aillada.

Però ara bé, què haguera ocorregut si aquesta opció no s'haguera pogut dur a terme i mai s'hagueren construït pous al secà? La resposta a aquesta qüestió, és molt important per a entendre la importància que tingueren les societats de reg en tot aquest procés de transformació agrària. Sense elles la superfície de regadiu i per tant del cultiu de la taronja a Vila-real mai haguera segut major a unes 30.000 fanecades. Aquesta xifra creiem que haguera sigut del tot insuficient per a que s'haguera materialitzat un veritable canvi del model econòmic tal i com el coneixem, ja que al reduir-se aproximadament en un $60 \%$ la superfície que s'arribaria a colonitzar amb cítrics, no s'haguera aconseguit una producció suficient, capaç de convertir la taronja en un motor industrialitzador.

A banda de la importància que pogueren tenir aquestes societats, val a dir que el procés d'expansió del regadiu no s'explica únicament amb la creació d'aquestes societats, sinó també amb l'exercici de "traure la terra"8. Tasca què es basa en la inversió en temps i força de treball per a fer aquestes terres aptes per al cultiu de la taronja. Feina que podien fer els mateixos propietaris o també jornalers contractats per terratinents, amb la utilització

7 Arribant, fins i tot, a desaprofitar-se l'aigua quan no hi havia sequera.

8 Verb utilitzat en la zona per a referir-se a la transformació de seca en regadiu. Un secà caracteritzat per la presencia de gran roques o penyes que impedien el cultiu de la taronja. 
de curioses formules com el "fiat", el "traure a mitges" o altres derivats que van fer possible l'accés a la xicoteta propietat per a un gran nombre d'individus, ja que a canvi de traure la terra, aquest obtenia una porció de la terra treta, sent la quantitat acordada prèviament.

\section{LA ReCERCA DELS SOCIS ADEQUATS: VINCLES I XaRXeS SOCIALS}

Un cop explicat l'origen de les societats de reg des del punt de vista més clàssic, començarem a reconstruir tot el procés de fundació. Aquest procés té el seu origen en la oralitat, ja sigui per l'iniciativa simultània d'un conjunt $d^{\prime}$ individus amb interessos comuns que decideixen unir-se o per l'iniciativa d'un sòl personatge, que amb una major visió de futur, major espenta a l'hora de prendre riscos econòmics, o amb la suficient consideració social com per a tenir una certa influència, aconsegueix convèncer a tot un seguit $d^{\prime}$ 'individus per a que realitzen l'experiència amb ell. Siga qui siga el propulsor, és important tenir present que aquest és un procés de llargues negociacions i reunions realitzades tal volta a dintre de les tavernes locals.

Dit açò, podem preguntar-nos, quins són els vincles personals que determinen l'associació entre una persona $o$ un altra $o$ si segueixen algun tipus de patró d'associament. A priori, podríem pensar que el factor més obvi per a comprendre aquestos vincles és l'aveïnament de terres. Evidentment a l'hora de unir-se és important que la superfície que vaja a ser regada no sigui excessivament gran, ja que de ser així podria ser una experiència no rentable. Com a exemple clar d'aquesta afirmació podem citar la xarxa de reguers, com més superfície, més kilòmetres de xarxa i per tant més costos a l'hora de construir-la i mantenir-la, ja que es multipliquen les possibilitats d'una fuga, un embussament, un robatori d'aigua...

Però ara bé, que les finques estiguen properes no significa que estiguen juntes, en origen la superfície regada era dispersa. Aquesta afirmació no es fàcil de justificar, ja que no sabem en aquell moment on estava situada cada finca, però hi ha alguna forma d'aproximar-nos. Si mirem les escriptures de compravenda de les finques on es construirien els futurs pous i comparem els noms dels propietaris de les terres contigües amb els noms dels fundadors ens trobem amb que tan sols el $12 \%$ dels propietaris contigus són socis, en origen, que no vol dir que no s'associen després?.

9 Per a traure aquest percentatge hem agafat 27 escriptures de compra venda, dels 92 propietaris que tenien terres contigües a la finca comprada, tan sols 11 eren socis de la sènia en qüestió. Fonts: Madrigal (1898), Agricultura Moderna (1899), Explotación Agrícola (1900), Fomento de la Agricultura (1900), Progreso del Hortal (1900), San Pascual (1900), San Isidro (1900), El Porvenir (1901), Unión Villarrealense (1901), Virgen de Gracia (1904), Segura (1904), Virgen 
Per què és important açò? Perquè si la concentració de terra haguera sigut total significaria que aquestos individus s'unien únicament entre veïns de camp, però al no ser així i existir un associament dispers de la terra podem parlar d'altres factors o vincles de tipus personal que determinen aquesta unió. Alguns d'aquests vincles no es poden calcular, com per exemple l'amistat, però hi ha altres que sí com ara, el veïnatge urbà o els vincles familiars. Pel que fa al primer, efectivament hi ha fundadors de determinades sènies que viven porta en porta, és cert que el percentatge no és molt alt, però si existent ${ }^{10}$. Tot $\mathrm{i}$ que cal advertir que aquest vincle concret pot ser fruit de la casualitat. Pel que fa als vincles familiars, aquests són molt més fiables que els anteriors i a més el percentatge és molt més elevat, tot i que tan sols podem conèixer el cas de germans per l'homonímia dels dos cognoms. Per a quantificar-lo vam agafar deu societats al atzar i vam veure que en totes hi havia germans, fins al punt de que aquestos vincles representen quasi un $20 \%$ dels fundadors ${ }^{11}$. Aquesta xifra agafa importància si tenim en compte que el $40 \%$ dels fundadors de totes les sènies estudiades tenen altres germans fundadors en la mateixa o diferent societat.

\section{Prosopografia dels socis fundadors i estructura de la propietat de les PRIMERES TERRES TRANSFORMADES}

Una volta vist açò, és inevitable preguntar-nos qui foren aquelles persones que donaren els primers passos per construir pous col.lectius. Dit açò, farem un ràpid repàs historiogràfic sobre les conclusions escrites fins ara respecte al perfil social dels fundadors de societats de reg, les quals ens donaran una hipòtesis de partida que tractarem d'ampliar.

Un dels primers en parlar directament sobre les característiques dels fundadors de societats de reg fou Emili Obiol, qui en una obra dedicada a

del Carmen (1905), San Pedro (1906), Unión Agrícola (1906), San Jaime (1911), La Bienvenida (1911), San Benito (1912), San Miguel (1912), Cristo del Hospital (1912), San Juan (1912), Hidro Agrícola (1912), Michá de la Tanda (1913), La igualdad (1913), Mijares (1913), Santa Quiteria (1913), San Gil (1913), San Vicente Ferrer (1913) i El Ebro (1913).

10 Per a quantificar el veïnatge urbà tan sols disposàvem del domicili dels fundadors de dos sènies: Santa Quiteria (1913) on trobem 3 veïns del carrer Major d'Almassora, així com tres veïns del carrer San Pascual i tres veïns del carrer Santa Clara de Vila-real i Hidro-Agrícola (1912) on troben 2 veïns del carrer Valle i 2 veïns del carrer Santa Clara de Vila-real.

11 De 388 fundadors 74 tenien germans. Fonts: Progreso del Hortal (1900), San Isidro (1900), Virgen de Gracia (1904), San Roque, San Jaime (1911), San Miguel (1912), San Juan (1912), Hidro-Agrícola (1912), La Fanguera i El Ebro (1913). 
la toponímia rural de Vila-real va agafar com a model l'escriptura fundacional de la societat "Virgen de Lourdes" i va arribar a la següent conclusió: el perfil social de fundador és el d'un baró, llaurador i casat de entre vint i seixanta anys (Obiol, E., 1986: 50). Dos dècades després, Samuel Garrido, en una obra dedicada a l'evolució de les estructures agràries a la Plana de Castelló, publicà l'estructura de la propietat referent a les sènies "San Benito" i "Unión Villarrealense" on es podia veure en les primeres finques associades un predomini de la petita propietat, tenint aquestes una extensió de entre 1,1 i 6 fanecades principalment (Garrido, S., 2004: 41).

Partint d'aquesta última afirmació, vam repetir aquest procediment a major escala documental. D'aquesta manera, al elaborar una estructura de la propietat conjunta entre les dades d'una cinquantena de sènies, vam traure uns resultats molt semblants a les xifres aportades per Samuel Garrido.

TAULA 1

Estructura de la propietat dels fundadors (1897-1914)

\begin{tabular}{|l|c|c|c|c|}
\hline & Fundadors & $\%$ & Fanecades & $\%$ \\
\hline Menys 1 & 86 & 5,3 & 82,0 & 0,8 \\
\hline 1,1 a 6 & 1003 & 62,2 & 3558,4 & 34,2 \\
\hline 6,1 a 12 & 354 & 22,0 & 3183,4 & 30,6 \\
\hline $12,1-18$ & 88 & 5,5 & 1313,3 & 12,6 \\
\hline $18,1-24$ & 47 & 2,9 & 980,8 & 9,4 \\
\hline més 24 & 34 & 2,1 & 1273,1 & 12,3 \\
\hline & 1612 & & 10391 & \\
\hline
\end{tabular}

Però, no obstant això, cal advertir que aquesta afirmació no ens mostrava una autèntica visió de conjunt. Perquè havíem de tenir en compte un detall molt important, i era que el $20,4 \%^{12}$ d'aquestos individus fundaren més d'una societat entre 1897 i 1914, transformant ells sols el $38,6 \%{ }^{13}$ de la superfície que hem estudiat en aquest mateix període. D'aquesta manera, crearem una nova estructura de la propietat que tingués en compte la repetició dels individus documentats en cada societat de regs. Per una banda, poguérem corroborar que les petites explotacions (de entre 1.1 i 6 fa) continuaren tenint un paper destacat ${ }^{14}$. Però, malgrat açò, la nostra aportació fou

12 D'unes 1217 persones, 248 estan repetits de la següent manera: 182 persones amb dos fundacions, $43 \mathrm{amb}$ tres, $11 \mathrm{amb}$ quatre, $5 \mathrm{amb}$ cinc i 1 amb sis.

13 De les 10998,8 fanecades transformades a regadiu que hem estudiat, 4254 pertanyen a fundadors repetits.

14 Com podem veure al quadre 2, el $87 \%$ dels fundadors tenen menys de 24,1 fanecades. 
la d'assenyalar que aquest predomini de la petita propietat, no significava necessàriament que anés lligada a un predomini del petit propietari.

\section{TAULA 2}

Estructura de la propietat sense individus repetits (1897-1914)

\begin{tabular}{|l|c|c|c|c|}
\hline & Fundadors & $\%$ & Fanecades & $\%$ \\
\hline Menys 1 & 79 & 6,6 & 64,7 & 0,6 \\
\hline 1,1 a 6 & 649 & 54,1 & 2302,6 & 20,8 \\
\hline 6,1 a 12 & 257 & 21,4 & 2309,5 & 20,9 \\
\hline $12,1-18$ & 97 & 8,1 & 1443,5 & 13,0 \\
\hline $18,1-24$ & 40 & 3,3 & 847,6 & 7,7 \\
\hline més 24 & 78 & 6,5 & 4095,8 & 37,0 \\
\hline & 1200 & & 11063,7 & \\
\hline
\end{tabular}

Molts d'aquells aparents petits propietaris que al parèixer tenien menys de 6 fanecades al quadre 1, posseïen en realitat altres lots de terra (dispersos i menuts), inclús en localitats veïnes. Aquestos no s'acontentaren en transformar una única finca menuda, sinó que ja ficats decidiren transformar-les totes o quasi totes en diferents sènies $i$ en un espai de temps mai superior a 15 anys per individu.

D'aquesta manera, al sumar totes eixes petites explotacions dels individus repetits poguèrem veure com s'augmentà significativament el nombre d'uns mitjans i gran propietaris que fins ara es trobaven ocults. L'exemple més clar és el següent: mentre que en al quadre 1 veiem que les terres de més de 24 fanecades tan sols representen un 12,3\%, al quadre 2 ascendeix fins al $37 \%$. Així doncs, el principal canvi interpretatiu que proposem és el fet de que més d'un terç de la superfície del secà transformat per socis fundadors entre 1897 i 1914, fou dut a terme per un grup poc nombrós de grans terratinents $(6,5 \%)$, principalment locals, ja que la presencia d'absentistes de València és purament anecdòtica ${ }^{15}$, lògic si tenim en compte que al 1900 aquests últims tan sols posseïen el 3,4\% del secà a Vila-real ${ }^{16}$.

Fins a cert punt, aquest augment en la presència de propietaris majors és lògica, ja que lligaria d'alguna manera amb el model d'estructura de la propietat que tenia el secà de Vila-real l'any 1900. Un model on les explotacions amb més de 24 fanecades representaven el 66,5\% de la superfície

15 Hem trobat 3 ciutadans de València a les següents sènies: San Pascual (1900), El porvenir (1901) i Vírgen del Carmen (1905) on fins i tot l'enginyer Enrique González-Grada Silva seria president.

16 GARRIDO, S. (2004: 97). 
i estava en mans del $22 \%$ dels propietaris, repetint-se la tònica general de que la major part de la terra es concentrava en poques mans ${ }^{17}$.

Però tot i això, i ací és on entra la peculiaritat del fenomen de la fundació de sènies, tot i existir com hem vist aquesta distribució desigual de la terra, els vertaders protagonistes, no són els que més tenen (més de 24 fa.), ni tampoc existeix un predomini tant destacat dels que tenen molt poc (menys de 6 fa.). Els vertaders protagonistes són un grup molt heterogeni d'individus, que transformaren el $54,7 \%$ del secà estudiat amb diversos lots de terra que podien sumar fins a 18 fanecades. Una xifra que de segur s'aniria ampliant posteriorment, ja que tan sols coneixem la quantitat de terra que associen en el moment de la fundació. El qual significa que podrien tenir més terres que associarien després, quan l'experiència es consolidés.

Arribats a aquest punt, si és cert que els primers fundadors formaren un grup heterogeni i complex, no ens podem aturar simplement amb l'anàlisi de la terra aportada per cadascú 18 . De manera que a continuació intentarem ampliar amb nous matisos el perfil social de fundador descrit per Emili Obiol, mitjançant l'ús de les escriptures fundacionals.

Aquestes fonts a banda de dir-nos el nom dels fundadors, els cognoms i la terra que associaren també ens descriven característiques personals d'aquestos individus. A partir de les referències a l'edat i a l'estat civil, val a dir que podem trobar una gran varietat social de fundadors. Tenim des de joves solters de 22 anys fins a ancians vidus de 89 anys, però, no obstant això, el col.lectiu quantitativament més significatiu serà el dels adults casats amb una mitjana de 45 anys. Aquesta xifra serà un poc diferent en el cas de les dones, ja que la seva minoritària presència (entorn al 10\%), agafa una importància relativa abans dels 30 anys, estant solteres, i després dels 50, al enviduar, per estar eclipsades legalment pels seus marits durant el matrimoni.

Totes aquestes dades, representades als gràfics 2 i 3, mostren que els primers fundadors són persones madures, que es troben en un moment de la seua vida idoni per assumir riscos econòmics, ja que la seua avançada edat es un reflex de que aquesta transformació del camp no es una maniobra per a augmentar l'autosuficiència sinó més bé una millora per a augmentar els seus beneficis amb el cultiu i l'exportació comercial de la taronja, al mateix temps que es promocionen socialment.

17 GARRIDO, S. (2004: 172-173).

18 Tinguem en compte que aquestes dades no desvelen les propietats totals de cada individu, tan sols la terra associada en el moment de la fundació. Que una persona associe una fanecada no vol dir que no en tinga moltes més. 
GRÀFIC 2

Edat dels fundadors en \% $(1897-1914)^{19}$

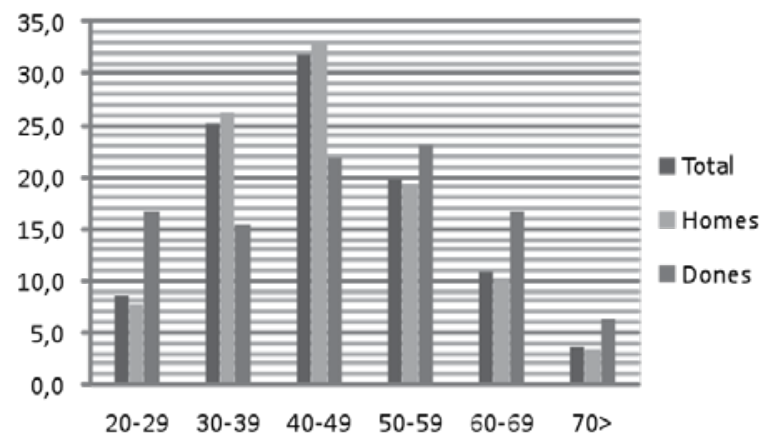

GRÀFIC 3

Estat civil dels fundadors en \%(1897-1914) $)^{20}$

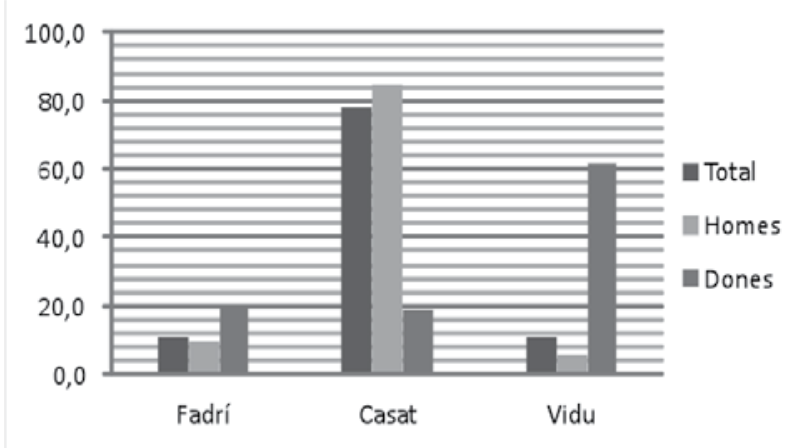

19 Per fer aquesta gràfica hem utilitzat 762 individus (684 homes I 78 dones), procedents principalment de 21 societats de reg. Fonts: San Marcos (1897 i 1902), Madrigal (1899), Camino Carretera (1899), El Pilar (1900), San Pascual (1900), San Isidro (1900), El Porvenir (1901), La Purificación (1901), Nueva Riqueza Territorial (1901), El Siglo XX (1901), Unión Villarrealense (1901), San Antonio (1901), Segura (1904), Virgen de Gracia (1904), Virgen del Carmen (1905), San Roque (1905), San Pedro (1906), La Fanguera (1906), Balsa de Insa (1906), Hidro-Agrícola (1912) i La Magdalena (1912).

20 Per a la realització d'aquest gràfic hem utilitzat 1.600 individus (1434 homes i 166 dones), procedents de les quaranta-set escriptures fundacionals citades a la bibliografia. 
Pel que fa als oficis, val a dir que hi ha una gran varietat en la ocupació laboral dels fundadors, des de metges fins a espardenyers ${ }^{21}$. Açò és lògic, ja que no tots els socis tenen perquè viure únicament del treball de les seues pròpies explotacions. Hi haurà individus amb poca terra que tenen que treballar la d'altres o buscar-se una ocupació no agrària en les ciutats per diversificar ingressos. De la mateixa manera que hi haurà altres socis propietaris més ben situats, fins i tot amb estudis superiors, que no tindran cap necessitat econòmica de treballar al camp, però que també protagonitzaran aquest procés.

Partint d'aquesta diversificació, destaca la presència de la triada formada per llauradors (53,3\%), propietaris $(18,5 \%)$ i jornalers $(4,4 \%)$. Amb aquestes dades es podria traure la conclusió de que aquest és un procés originat principalment per llauradors que viuen de treballar la seua pròpia terra, per damunt dels propietaris que viven de rentes o dels jornalers que són a priori petits propietaris que es veven obligats a llogar-se al camp. No obstant, aquesta és una visió tradicional que cal matisar.

Cal tindre en compte que aquestos no són grups immòbils o estàtics, hi ha una veritable mobilitat entre aquestes tres ocupacions laborals o millor dit consideracions socials, de manera que una mateixa persona pot figurar en una escriptura com a jornaler i a l'any següent com a llaurador o inclòs com a propietari. Aquestos canvis es fan en un alt percentatge de baix a dalt, el qual podria ser un indici de la hipòtesis de que construir una sènia enriqueix. Tant a mitja termini, quan els tarongers comencen a ser productius, de huit a deu anys després, com també a curt, perquè augmenta el valor de la terra de forma immediata, com veurem després.

Així doncs, per a concloure aquest punt, val a dir, que el perfil social d'aquestos individus és prou complex. No estem davant d'un grup homogeni que es puga seguir definint simplement com un conjunt de "petits llauradors". La construcció d'aquestos pous suposava una despesa tan elevada que fins i tot els grans terratinents havien d'associar-se amb gent que aparentment tenia menys que aportar a la societat. Però ara bé, la nostra intensió no és la de mostrar diferències internes entre fundadors més rics i fundadors més pobres. El que volem mostrar és que el llaurador de la Plana no és un personatge passiu, que deixe fer als que més tenen. Més bé al

21 Dividits per sectors laborals podem dir que el 59\% dels fundadors corresponen al sector primari (llauradors, jornalers, fusters, carboners, calciners, picapedrers, pastors i vaquers); el $7 \%$ al secundari (sabaters, paletes, pintors, confiters, forners, teixidors, tintorers, matalassers, ferrers, llauners...); el $8 \%$ al terciari (comerciants, empleats, metges, carnissers, advocats, mecànics, farmacèutics, enginyers, professors, barbers, taverners, electricistes, veterinaris...) i finalment, el $26 \%$ corresponen a propietaris, militars, religiosos, aturats, llavors domèstiques. 
contrari, són individus dinàmics i d'una gran mobilitat social que s'associen amb grans terratinents sense cap tipus de pudor, ja que tenen una visió comercial de l'agricultura desenvolupada durant generacions i no els importa fer front a les dures despeses de la construcció del pou perquè saben que acabaran beneficiant-se.

Prendre riscos com aquestos, no suposaren res nou per a ells. De manera què, seguint aquest criteri, interpretem que aquestes societats de reg no naixen a finals del segle XIX com a conseqüència d'un canvi sobtat en la mentalitat del llaurador. Sinó més bé per la conjuntura de dos factors: una tecnologia industrial adequada i un context econòmic favorable.

\section{Organització i administració de les societats de reg des de la creació LEGAL FINS A LA CONSTRUCCIÓ FISICA DEL POU}

Aquests individus s'agruparen, en origen, en societats per al "alumbramiento y elevación de las aguas y su aprovechamiento para el riego de los campos de que se hallan en posesión ${ }^{\prime \prime 2}$, composades per una mitjana de 35 socis $^{23}$ que creaven noves zones regables d'una mitjana de quasi 230 fanecades ${ }^{24}$, que com ja hem dit, estaven compostes per finques properes però no necessariament limítrofes tot i que al futur la superfície "podría ampliarse siempre que el caudal de agua sea abundante, advirtiéndose al beneficio del riego los nuevos precios que acuerde la sociedad" $25, \mathrm{i}$ "siempre que no haya pretendientes de los individuos que compongan la expresada zona, los cuales tendrán preferencia sobre los extraños" ${ }^{\prime 26}$.

No obstant això, crear una societat de regs, no consistia únicament en buscar companys amb inquietuds semblants per a construir el pou i ficar-se a regar. El procés era molt més complex, doncs entre altres coses hi havia que decidir conjuntament el regim intern de la societat, quins serien els seves drets i deures, com solucionar conflictes, com organitzar la construcció del futur pou...

\section{Societat "San Gil" (1913).}

23 El nombre de fundadors d'una sènia varia molt, trobem casos com la societat "La Magdalena" (1912) que va ser originada per 12 persones o altres casos com la societat "San Roque" (1905), que per contra, fou originada per 104 socis.

24 El mateix que amb el nombre de fundadors, ocorre amb la terra, podem trobar casos com la societat "La Fanguera" (1906) amb una superfície inicial de 305 fanecades o altres menors com la societat "San Antonio" (1902) amb 102 fanecades en origen.

25 Societat "San Gil" (1913). En altres societats com "El San Benito" (1912) s'insisteix en que no s'ampliarà l'àrea regable "mientras se desconozca el caudal de aguas obtenido".

26 Societat "San Benito" (1912). 
Un aspecte prou interessant és el sistema de pagament, un sistema basat en els dividends que eren aportacions periòdiques o extraordinàries dels socis dutes a terme per a fer front a les despeses "en proporción al número de hanegadas y fracciones de ésta que posea cada socio"27. Mitjançant l'ús de paperetes firmades pel president i repartides a domicili amb "el canon para el riego a la tarifa y condiciones que establezca la Junta Gestora o directiva" ${ }^{\prime \prime 2}$. El incompliment d'aquests pagaments podia ocasionar la pèrdua dels drets com a soci.

Pel que fa al repartiment de l'aigua el més comú és que cada soci tingués dret a l'ús d'un únic portell dels reguers del pou, a no ser que tingués una concessió expressa de la Junta Gestora o Directiva. Tot ordenat sempre al voltant dels "torns de reg", organitzats per la Junta General, on sempre es buscava les combinacions més beneficioses per a tots els socis a més de tindre en compte la climatologia $i$ altres factors que pogueren alterar el ritme natural del reg. Si es donava el cas de que una volta acabat el torn, sobrava aigua, els socis que ho veiessin convinent podien utilitzar-la fora del seu torn per a regar, tot i que en aquest cas serien aquestos els que tindrien que fer-se càrrec de les despeses de "movida y consumo". Si encara així quedava aigua de sobra i ningú tenia la necessitat de utilitzar-la, la Junta General podia acordar vendre l'aigua, que en molta documentació es denomina com a potable, per a traure beneficis extraordinaris i o bé repartir els beneficis entre els socis o ingressar-lo en el fons comú. Per altra banda, els socis tenien el dret de deixar passar el seu torn de reg, però això sí, sense possibilitat de recuperar-lo. Finalment, també es troben referències a la mala utilització de l'aigua, multes per furts ${ }^{29}$ o per regar en terres no associades ${ }^{30}$.

Pel que fa a la transmissió del dret d'aigua, es interessant tindre en compte que ser membre d'una societat de regs no estava subscrit a la persona sinó a la terra transformada, en cas de compravenda o herència, els nous propietàries continuarien podent regar en una societat, amb una "zona regable, de carácter permanente o de duración indefinida [que] subsistirá mientras cumpla sus fines" ${ }^{1 / 31}$.

27 Societat "San Gil" (1913).

28 Societat "El Ebro" (1913).

29 Societat "San Gil" (1913): la multa per robar aigua era de 150 pessetes per metre quadrat regat.

30 Societat "San Gil" (1913): es pagava de una a cinc pessetes per metre quadrat regat fora la terra associada.

31 Societat "El Ebro" (1913). 
Un altra qüestió reglamentada fou el còmput de vots en Junta General, que és on estaven representats tots els socis. Amb aquestes votacions es prendrien decisions conjuntes i es renovaria la Junta Directiva periòdicament. Unes votacions que a més seran molt variades, ja que podrem trobar un gran nombre de fórmules per al còmput de vots, des de societats on donen més importància a l'individu i per tant cada persona és un vot, fins a altres on es dóna més importància a la terra aportada, de manera que "hasta una hanegada un voto, hasta dos, dos, hasta tres, tres y así sucesivamente ${ }^{132}$. Aquestes diferències pensem que són importants, però no hem sigut capaços de trobar ninguna explicació empírica que ens puga ajudar a comprendre en que es basen per a elegir una fórmula de vot o un altra, tal volta el pes social dels individus amb més terra seria una possible aproximació.

A banda d'aquestes mesures, fonamentals per al bon funcionament teòric de les societats al futur, per a conèixer millor les sènies en aquestos primers anys és vital estudiar les Comissions Gestores, ja que foren l'òrgan intern destinat a la administració i organització de les societats fins a la construcció física del pou. Les seues tasquen eren principalment aquestes: "llevar a cavo todas las obras de esta empresa y representar a la sociedad en todos los asuntos de su interés; Adquirir la maquinaria y artefactos para la elevación de las aguas del pozo y contratar su emplazamiento y las obras de construcción que sean necesarias, por los precios, plazos y condiciones que estipulen ${ }^{33}$; Señalar la dirección y trazado de todos los regueros y expropiar a los socios los terrenos que se necesiten (...) ocupando temporalmente los que exijan el transporte de la construcción sin que los socios puedan oponerse ni impedirlo bajo ningún pretexto; Nombrar el maquinista, auxiliar de contabilidad y demás personal subalterno que exija la buena marcha de la sociedad 34 , asignándole el sueldo que crean conveniente; Hacer las convocatorias a los socios para las reuniones generales ${ }^{35}$, las que presidirá y dirigirá sus deliberaciones; Administrar los fondos sociales dándoles el destino que corresponda a la empresa, cuenta y razón de sus ingresos y gastos cuyo balance expondrá cada tres meses para conocimiento de los socios en la tablilla de anuncios de la casa donde exista el pozo"136.

32 Societat "San Pascual" (1900).

33 Els diners necessaris per a la realització d'aquestes tasques eren aportats pels socis en dividends extraordinaris. Uns dividends que de no ser pagats en el termini acordat podien ser motiu d'expulsió de la societat.

34 Podríem ampliar la llista de personal subaltern amb els càrrecs de regador, avisador i recaptador.

35 Quan ens tinguem que referir-nos a "reuniones generales" utilizaren l'expressió "Junta General".

36 Societat "San Gil" (1913). 
Aquestes comissions gestores estaven formades per un president que "representará legalmente á la sociedad en juicio y fuera de él pudiendo exigir ante los Tribunales de justicia el pago de los dividendos que se repartan á los socios y el cumplimiento de las demás obligaciones que contraiga a la sociedad; deberá convocar a la Junta Directiva y á la general cuando sea necesario ó conveniente: dirigirá sus discusiones y ejecutará sus acuerdos; confirmándose al efecto el poder especial y necesario que en derecho se requiera" ${ }^{137}$, un vicepresident, un secretari, un depositari que "guardará bajo su custodia los fondos de la sociedad y satisfará los gastos que le ordene el presidente, rindiendo a su día oportuna cuenta"38 a més de dos a cinc vocals.

Però, la pregunta que cal fer-se és, qui formava part d'aquest primer òrgan gestor? En qualsevol d'aquestos càrrecs es reitera el perfil estàndard d'homes $(100 \%)$, casats $(80,3 \%)$ i d'edat madura (41,6 anys) sent l'ocupació i la terra aportada les úniques dades diferenciadores entre càrrecs. Pel que fa a l'ocupació laboral o consideració social, s'observa una majoria de propietaris com a presidents $(40 \%)$, una majoria de llauradors com a vicepresidents $(46 \%)$, mentre que als càrrecs de secretari i depositari no hi ha una ocupació dominant. Pel que fa a la quantitat de terra aportada, tot $\mathrm{i}$ que podria ser coincidència, cada càrrec aporta unes quantitats diferenciades, de manera que de més a menys tenim als presidents amb una mitjana de 30 fanecades, els depositaris amb 13,6, els vicepresidents amb 11,5 i finalment els secretaris amb 6,5 fanecades ${ }^{39}$. Així doncs, aquestes dades, tot i ser molt discretes i superficials, podrien estar indicant-nos una lleugera diferenciació social alhora d'aspirar a la gestió de la primitiva societat? Per altra banda, cal tenir en compte l'existència d'individus que tenen càrrecs en diverses comissions gestores alhora, que tal volta desvelen l'existència d'especialistes en l'administració de sènies, des dels seus orígens.

Una volta complit el seu comès, la Comissió Gestora "rendirá cuentas de la inversión de lo recaudado, y aprobadas que sean estas cuentas, cesará

37 Societat "Explotación Agrícola" (1900).

38 Societat "Explotación Agrícola" (1900).

39 Fonts: Fomento Agrícola (1900), Progreso del Hortal (1900), El Pilar (1900), Explotación Agrícola (1900), San Isidro (1900), La Bienvenida (1900), San Antonio (1901), La Purificación (1901), Nueva Riqueza territorial (1901), El siglo XX (1901), San Marcos (1902), Virgen de Gracia (1904), Segura (1904), Virgen de Lourdes (1904), Virgen del Carmen (1905), Corazón de Jesús (1905), La Fanguera (1906), Unión Agrícola (1906), Balsa de Insa (1906), San Jaime (1911), San Juan (1912), San Benito (1912), San Miguel (1912), Hidro-Agrícola (1912), Cristo del Hospital (1912), La Magdalena (1912), San Gil (1913), El Ebro (1913), Santa Quiteria (1913), La Igualdad (1913), San Vicente Ferrer (1913) i El Millars (1914). 
dicha Junta en sus funciones", donant pas a una Junta Directiva "para que se encargue de la dirección y distribución del riego y administración de los intereses de la sociedad", a més de convocar la Junta General on estaven representats tots els socis. Posteriorment, "Una vez se obtenga el agua necesaria para el riego de la zona destinada á este objeto y queden terminadas las obras y emplazadas la maquinaria y artefactos en perfecto estado de funcionamiento, la Junta General acordará también el nuevo contrato o reglamento sobre régimen interior de la sociedad y la forma y distribución de los riegos y cuanto sea pertinente á la buena marcha de si misma, así como caso de no obtener éxito la empresa después de hechos todos los trabajos necesarios, la continuación ó desistimiento de las obras; sometiéndose desde luego los socios á la ejecución de tales acuerdos, siempre que se tomen por mayoría absoluta de votos según el cómputo establecido"40.

\section{Reflexions al voltant dels cultius I dels preus de la terra abans de ser TRANSFORMATS A REGADIU}

Fins ara hem estat parlant principalment d'un tipus molt concret de documentació, les escriptures fundacionals, però per al punt que ara ens pertoca, val a dir, que no sols utilitzarem aquestes fonts, sinó que també estudiarem la documentació notarial referent als exercicis de compravenda col.lectiva de les finques que més tard serien perforades per a construir els pous. Moltes vegades aquesta important part del procés fundacional va unida a la creació de la societat, el qual vol dir que s'havia fet un acord previ amb el propietari (siga soci o no). Altres vegades, per contra, els socis van al notari sense saber exactament on construiran el pou, sent aquest el motiu pel qual a voltes hi ha que buscar aquestes compravendes per separat.

Dit açò, val a dir què l'estudi d'aquestes compravendes col-lectives ens permet tindre una visió superficial sobre els preus de la terra i els cultius immediatament anteriors a la implantació del tarongerar.

Si ens aturem a observar la tipologia de cultius presents a les compravendes de les finques on es construiria els futurs pous, veiem que en aquestos moments destaca la majoritària presència de les terres cultivades amb la garrofera $(56,1 \%)$, seguit per la vinya $(19,5 \%)$ i altres com la figuera, la 
olivera i terres campes en menor mida ${ }^{41}$. Aquestes dades són, com es podia imaginar, un veritable reflex de l'ús de la terra al secà de Vila-real durant el segle XIX. Açò és així, degut per exemple al predomini de la garrofera, ja que a l'any 1882, uns quinze anys abans d'iniciar-se aquesta experiència, encara constituïa el principal cultiu del secà vila-realenc, entorn al $85 \%$ (Garrido, S.. 2004: 163).

Però ara bé, com ja han assenyalat diversos autors, no hi ha que pensar que a finals del segle XIX i principis del XX existeix un secà endarrerit que haja de ser necessariament transformat a regadiu. No hem d'oblidar què aquestos cultius tradicionals tenen diverses utilitats, on destaca fins i tot una veritable funció comercial què en el cas de la garrofera es remunta com a mínim al segle XVIII.

Desenvolupant aquesta última idea, pensem que la creació de societats de reg no ha de veure's com una gran ruptura, ja què tal volta no és més que la continuïtat d'una mentalitat comercial que pogué consolidar-se, com ja hem dit, quan tingué la conjuntura idònia. D'aquesta conjuntura cal destacar, per la naturalesa d'aquest article, la incorporació de maquinaria industrial al camp, com el motor a vapor, sent aquesta eina el nucli fonamental de tota sènia i què a més desenvoluparia al seu voltant nous tipus de treballs especialitzats (com el maquinista), així com indústries paral.leles destinades a la seua fabricació, venta i reparació.

Per altra banda, transformar el secà, no tenia com a únic benefici els guanys de la taronja, sinó que aquesta "inversió" multiplicava el valor de la terra estigués o no cultivada amb tarongers. D'aquesta manera segons l'excepcional referència que trobarem a l'escriptura fundacional de la societat "San Marcos" al 1897, les primeres finques associades a un futur pou

41 Tipologia de cultius a les finques comprades per a construir els pous de reg en \% (1897-1914): Garroferes $(56,1 \%)$, vinya $(19,5 \%)$, terra mixta $(9,8 \%)$, secans $(7,3 \%)$, terra inculta $(4,9 \%)$, hort (2,4\%). Fonts: San Marcos (1897), Madrigal (1899), Agricultura Moderna (1899), Explotación Agrícola (1900), San Pascual (1900), Sense nom a Castelló (1900), Fomento de la Agricultura (1900), Progreso del Hortal (1900), El Pilar (1900), La Purificación (1901), San Antonio (1901), La Nueva riqueza territorial (1901), El Siglo XX (1901), El Porvenir (1901), Neptuno (1902), La Unión Hidráulica (1902), San Marcos (1902), Virgen de Lourdes (1904), Virgen de Gracia (1904), Segura (1904), San Roque (1905), Corazón de Jesús (1905), Virgen del Carmen (1905), La Fanguera (1906), Unión Agrícola (1906), Balsa de Insa (1906), San Pedro (1906), San Jaime (1911), Hidro-Agrícola (1912), Cristo del Hospital (1912), San Juan (1912), La Magdalena (1912), San Miguel (1912), Santa Quiteria (1913), San Vicent Ferrer (1913), San Gil (1913), La Igualdad (1913) i El Millars (1914). 
augmentaren el valor de les explotacions de la següent manera: les terres cultivaves amb vinya augmentaren en 2,82 pessetes/fanecada, les de garroferes amb 3,8, i les de tarongerar $r^{42}$ amb 5 pessetes/fanecada.

La pregunta que ens formularem a continuació fou, si aquesta possibilitat de millorar el valor de l'explotació generà algun canvi representatiu en el mercat de la terra. De manera què, com es pot veure al gràfic 4 , els preus no es dispararen de forma exagerada com a resposta a un teòric augment de la demanda. Els preus seguiren més o menys estables i la seues lleugeres diferències és corresponien més bé a la suma d'altres factors com ara la localització de l'explotació o la qualitat del sòl.

Així doncs, en aquestos primers anys del procés, els fundadors de sènies, no tenien tanta "fam de terra" com podríem haver imaginat en un principi. Açò es devia a que la major part dels llauradors i terratinents ja disposaven de secans. Un exemple és que a Vila-real, l'any 1900 el 60\% dels propietaris ja en tenien (Garrido, S., 2004: 58). Per altra banda, el $64 \%$ de les terres venudes per a construir pous, havien arribat als venedors en forma d'herència ${ }^{43}$.

I és què, posseir secà, era quasi tant important com posseir regadiu, no era per a res una possessió menyspreada, ja que es complementaven l'una a l'altra. Dit açò, podríem dir que en aquestos moments inicials els fundadors no tenien una necessitat majoritàriament de comprar secà per a transformar-lo, ja què una part important d'ells transformaren la terra que ja tenien, encara que efectivament, existiren també els que associaren unes finques adquirides de forma molt recent ${ }^{44}$.

\section{Conclusions}

Com hem pogut veure al llarg d'aquest article, les societats de reg de la Plana de Castelló representen un clar reflex de l'evolució econòmica i social d'aquesta àrea geogràfica, si més no aplicable a altres comarques valencianes. Les sènies, són per tant, un nou mirall des de on es pot conèixer amb més detall tant processos econòmics referents a la industrialització del

42 L'aigua provenia de la Rambla de la vídua, però amb un pou la disponibilitat d'aigua era més regular. La qual cosa vol dir que en aquestos primers anys també es feien pous per a consolidar el reg, com passava també a l'horta de Borriana quan l'any 1912 es fundà la societat "Michà de la Tanda".

43 Veure Apèndix 2.

44 A l'apèndix 2 podem veure alguns exemples. Per exemple el venedor de la terra on es perforaria el pou "Madrigal" fou adquirida pel venedor aquell mateix any. 


\section{GRÀFIC 4}

Evolució dels preus del secà per fanecada i cultiu abans de ser transformats $(1899-1914)^{45}$

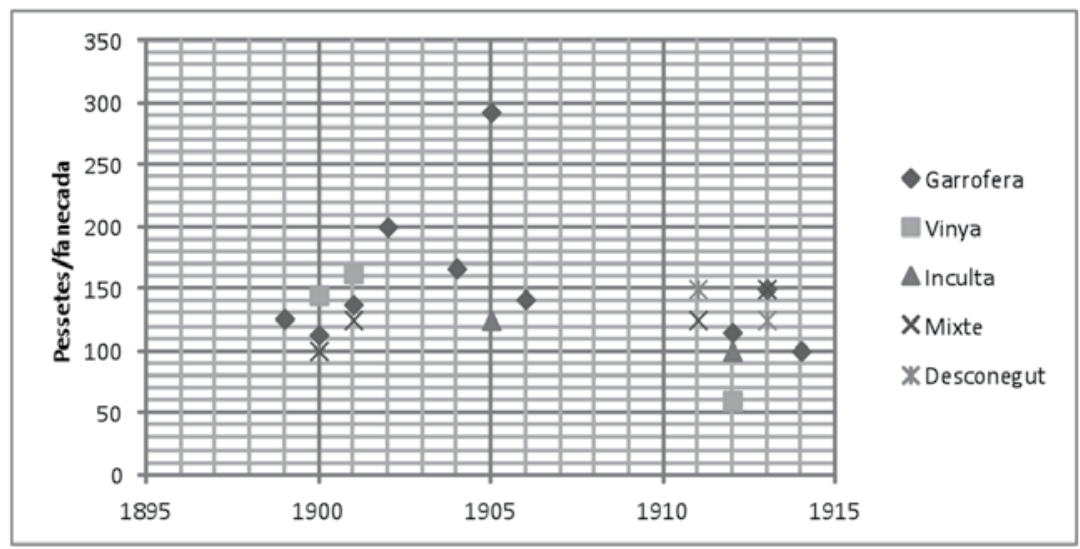

camp, la transformació dels secans i l'expansió del tarongerar, com aspectes socials relacionats amb l'associacionisme agrari.

Per alta banda, hem vist què aquesta experiència sorgeix sota una conjuntura molt concreta, més degut a les possibilitats oferides per les noves tecnològics industrials, què per una ruptura amb la mentalitat d'aquells llauradors. Uns llauradors, què constituint un grup heterogeni i complex, aplicaren una volta més el seu dinamisme, però amb la diferència respecte a experiències anteriors, de què seria aquesta la que convertiria el cultiu d'un fruit, com la taronja, en el motor industrialitzador de gran part del País Valencià.

45 La terra mixta fa referència als següents cultius: figueral/vinya, figueral/garrofa, figueral/olivera i vinya/olivera. Fonts: Agricultura Moderna (1899), Explotación Agrícola (1900), Fomento de la Agricultura (1900), Progreso del Hortal (1900), El Pilar (1900), La Purificación (1901), San Antonio (1901), La Nueva riqueza territorial (1901), El Siglo XX (1901), El Porvenir (1901), Neptuno (1902), La Unión Hidráulica (1902), San Marcos (1902), Virgen de Lourdes (1904), Virgen de Gracia (1904), Segura (1904), San Roque (1905), Corazón de Jesús (1905), Virgen del Carmen (1905), La Fanguera (1906), Unión Agrícola (1906), Balsa de Insa (1906), San Pedro (1906), San Jaime (1911), Hidro-Agrícola (1912), Cristo del Hospital (1912), San Juan (1912), La Magdalena (1912), San Miguel (1912), Santa Quiteria (1913), San Vicent Ferrer (1913), San Gil (1913), La Igualdad (1913) i El Millars (1914). 
Apèndix 1

Societats de reg consultades (1897-1914)

\begin{tabular}{|c|c|c|c|c|c|c|c|c|c|c|}
\hline \multirow{2}{*}{$\frac{N^{\circ}}{1}$} & \multirow{2}{*}{$\begin{array}{l}\text { SOCIETAT DE REGS' } \\
\text { San Marcos }\end{array}$} & \multicolumn{3}{|c|}{ DATA FUNDACIÓ } & \multirow{2}{*}{$\frac{\text { CIUTAT }^{2}}{\text { Alm }}$} & \multirow{2}{*}{$\begin{array}{l}\text { PARTIDA RURAL } \\
\text { Pla de Museros }\end{array}$} & \multirow{2}{*}{$\begin{array}{l}\text { SOCIS } \\
16\end{array}$} & \multicolumn{2}{|c|}{ TERRA $^{4}$} & \multirow{2}{*}{$\begin{array}{c}\%^{5} \\
11,8\end{array}$} \\
\hline & & 5 & 10 & 1897 & & & & 188 & 129 & \\
\hline 2 & Madrigal & 11 & 12 & 1898 & Vil & Madrigal & 48 & 300 & & 6,3 \\
\hline 3 & Fomento Agrícola & 5 & 10 & 1899 & Vil & & 43 & 284 & & 6,6 \\
\hline 4 & Agricultura Moderna & 28 & 11 & 1899 & Vil & Madrigal & 29 & 306 & & 10,6 \\
\hline 5 & Camino Carretera & 31 & 12 & 1899 & Vil & Pinella & 28 & 254 & 100 & 9,1 \\
\hline 6 & Explotación agrícola & 28 & 1 & 1900 & Vil & Pla Redó & 39 & 249 & 150 & 6,4 \\
\hline 7 & Fomento de la Agricultura & 25 & 2 & 1900 & Vil & Sella (Pinella) & 24 & 275 & & 11,5 \\
\hline 8 & Progreso del Hortal & 10 & 3 & 1900 & Vil & Masía del Palleter & 26 & 259 & 7 & 10,0 \\
\hline 9 & "Almassora-Villarroja" & 15 & 5 & 1900 & Alm & Vilarrocha & 32 & & & \\
\hline 10 & San Pascual & 17 & 5 & 1900 & Vil & Pla Redó & 32 & 303 & & 9,5 \\
\hline 11 & San Isidro labrador & 4 & 11 & 1900 & Vil & Pla Redó & 21 & 176 & 100 & 8,4 \\
\hline 12 & EI Pilar & 11 & 11 & 1900 & Vil & Madrigal & 34 & 200 & 100 & 5,9 \\
\hline 13 & Sin Nombre & 27 & 12 & 1900 & Cas & Estepar & & & & \\
\hline 14 & $\begin{array}{l}\text { El Siglo XX } \\
\text { La Nueva Riqueza }\end{array}$ & 18 & 1 & 1901 & Alm & Boverot & 31 & 286 & 72 & 9,2 \\
\hline 15 & Territorial* ${ }^{*}$ & 27 & 1 & 1901 & Vil & Salt (lindant amb Bechí) & 24 & 266 & 100 & 11,1 \\
\hline 16 & La Purificación* & 2 & 2 & 1901 & Vil & Barranco Ratils & 33 & 219 & 140 & 6,7 \\
\hline 17 & El Porvenir & 5 & 3 & 1901 & Vil & Partida del Salt (pla redó) & 39 & 230 & 11 & 5,9 \\
\hline 18 & San Antonio & 17 & 3 & 1901 & Vil & Pla Redó & 21 & 102 & & 4,9 \\
\hline 19 & Unión Villarrealense & 19 & 3 & 1901 & Vil & Miralcamp & 23 & 256 & 95 & 11,2 \\
\hline 20 & sense nom $[\mathbf{R}]^{*}$ & 26 & 5 & 1901 & Cas & Estepar & & & & \\
\hline 21 & San Marcos [R] & 8 & 6 & 1902 & Alm & Pla de Museros & 25 & 242 & 150 & 9,7 \\
\hline 22 & Almazorcense & 8 & 6 & 1902 & Alm & Vilamancarro & & & & \\
\hline 23 & Neptuno* & 14 & 9 & 1902 & Cas & Estepar & 40 & 199 & & 5,0 \\
\hline 24 & La Unión Hidráulica & 28 & 12 & 1902 & Cas & Estepar & 48 & 265 & 100 & 5,6 \\
\hline 25 & La Unión Hidráulica [R] & 14 & 1 & 1903 & Cas & Estepar & & & & \\
\hline 26 & Virgen de Gracia & 10 & 7 & 1904 & Vil & Pinella & 37 & 275 & & 7,4 \\
\hline 27 & Segura & 8 & 12 & 1904 & Vil & Caseta de Bellot o Camino Artana & 70 & 431 & 50 & 6,2 \\
\hline 28 & Virgen de Lourdes & 9 & 12 & 1904 & Vil & Corral Roig & 18 & 138 & & 7,7 \\
\hline 29 & Virgen del Carmen & 18 & 6 & 1905 & Vil & Pinella & 52 & 300 & & 5,8 \\
\hline 30 & Corazón de Jesus & 16 & 7 & 1905 & Vil & Algibe de Monfort (pinella) & 46 & 223 & & 4,8 \\
\hline 31 & San Roque & 19 & 11 & 1905 & Vil & Madrigal & 104 & 267 & 28 & 2,6 \\
\hline 32 & San Pedro & 4 & 2 & 1906 & Vil & Masía de los Frailes & 51 & 284 & 130 & 5,6 \\
\hline 33 & La Fanguera & 18 & 2 & 1906 & Vil & Pinella & 48 & 350 & & 7,3 \\
\hline 34 & Unión Agrícola & 29 & 7 & 1906 & Vil & Camino Bechí & 64 & 243 & 24 & 3,8 \\
\hline 35 & Balsa de Insa & 26 & 8 & 1906 & Vil & Balsa de Insa & 29 & 248 & 100 & 8,6 \\
\hline 36 & San Jaime & 21 & 8 & 1911 & Vil & Pla Redó & 33 & 178 & & 5,4 \\
\hline 37 & La Bienvenida & 8 & 12 & 1911 & Vil & Masía del soldado & 32 & 197 & & 6,2 \\
\hline 38 & San Benito & 14 & 1 & 1912 & Vil & Pinella & 41 & 380 & 100 & 9,3 \\
\hline 39 & San Miguel & 28 & 1 & 1912 & Vil & Pinella & 33 & 143 & & 4,3 \\
\hline 40 & Cristo del Hospital & 28 & 1 & 1912 & Vil & Pinella & 33 & 210 & & 6,4 \\
\hline 41 & La Magdalena & 21 & 4 & 1912 & Vil & Barrach Roig & 13 & 147 & & 11,3 \\
\hline 42 & San Miguel [R] & 30 & 6 & 1912 & Vil & Pinella & 37 & 170 & 100 & 7,4 \\
\hline 43 & San Juan & 22 & 12 & 1912 & Vil & Pinella & 23 & 170 & & 7,4 \\
\hline 44 & Hidro-Agrícola & 22 & 12 & 1912 & Vil & Masía del soldado & 18 & 126 & & 7 \\
\hline 45 & Micha de la Tanda & 26 & 12 & 1912 & Bur & Michá & 27 & 192 & 111 & 7,1 \\
\hline 46 & La Igualdad & 9 & 2 & 1913 & Vil & Pla Redó & 43 & 206 & & 4,8 \\
\hline 47 & El Mijares & 23 & 2 & 1913 & Vil & Molino de Enllop & 37 & 221 & & 6,0 \\
\hline 48 & Santa Quiteria & 27 & 2 & 1913 & Alm & Boverot & 30 & 209 & & 7,0 \\
\hline 49 & San Gil & 25 & 3 & 1913 & Vil & Pinella & 40 & 205 & 100 & 5,1 \\
\hline 50 & San Vicente Ferrer* & 6 & 4 & 1913 & Vil & Masía de los Frailes & 37 & 181 & & 5,2 \\
\hline 51 & El Ebro & 6 & 11 & 1913 & Vil & Pinella & 30 & 112 & 100 & 3,8 \\
\hline 52 & El Millars & 11 & 1 & 1914 & Vil & Balsa de Sarthou (Pinella) & 22 & 136 & 60 & 6,2 \\
\hline
\end{tabular}

$46\left[{ }^{*}\right]$ fa referència a societats que tot $\mathrm{i}$ ser constituïdes legalment, no perforaren pous.

$[R]$ fa referència a escriptures sobre refundacions o ampliacions de socis.

47 (Alm) Almassora, (Vil) Vila-real, (Bur) Burriana i (Cas) Castelló de la Plana.

48 Cal advertir que a les fonts moltes societats de la partida Madrigal surten com a Pinella.

49 La primera columna fa referència al nombre de fanecades i la segona al de braces.

50 Percentatge de fanecades aportades per fundador. 
Compravenda de terres per a les construccions dels pous (1897-1914)

\begin{tabular}{|c|c|c|c|c|c|c|c|c|c|c|}
\hline $\mathbf{N}^{\circ}$ & SOCIETAT DE REGS & ANY & CIUTAT & VENEDOR DE LA FINCA & FINCA $^{6}$ & Pts. ${ }^{7}$ & $1 \mathrm{fa}^{8}$ & CULTIU' & ACCÉS ${ }^{10}$ & \\
\hline 1 & San Marcos & 1897 & Alm & José Chabrera Batalla & 183 & 39,50 & 0,25 & Vinya & Comprada & 1982 \\
\hline 2 & Madrigal & 1898 & Vil & Marcelino Vicent Gurrea & 100 & 125 & & Vinya & Comprada & 1898 \\
\hline 3 & Fomento Agrícola & 1899 & Vil & & & & & & & \\
\hline 4 & Agricultura Moderna & 1899 & Vil & Manuel Molina Ortells & 1 & 126 & 126 & Garrofa & & \\
\hline 5 & Camino Carretera & 1899 & Vil & & & & & & & \\
\hline 6 & Explotación agrícola & 1900 & Vil & José Herrero Roca & 1 & 113,08 & 113,08 & Garrofa & Comprada & 1899 \\
\hline 7 & Fomento de la Agricultura & 1900 & Vil & Antonio Planes Llorens & 1 & 140 & 140 & Vinya & Heretada & 1881 \\
\hline 8 & Progreso del Hortal & 1900 & Vil & Bautista Franch García & 1 & 150 & 150 & Vinya & Heretada & 1899 \\
\hline 9 & "Almassora-Villarroja" & 1900 & Alm & Cristobal Colera Torrejón & 4 & 25 & & & Heretada & 1880 \\
\hline 10 & San Pascual & 1900 & Vil & Bárbara Petit Bosquet & 1 & & & Secà & Heretada & \\
\hline 11 & San Isidro labrador & 1900 & Vil & Ana María Pesudo Gil & 1 & 100 & 100 & & Heretada & 1895 \\
\hline 12 & El Pilar & 1900 & Vil & Salvador Sifre Beltrán & 1 & 100 & 100 & Figa/Viña & Comprada & 1900 \\
\hline 13 & Sin Nombre CAS & 1900 & Cas & & & & & Viña & & \\
\hline 14 & El Siglo XX & 1901 & Alm & Manuel Esteller jorda & 1 & 150 & 150 & $\begin{array}{l}\text { Viña } \\
\text { Figa/ }\end{array}$ & Heretada & 1896 \\
\hline 15 & La Nueva Riqueza Territorial* & 1901 & Vil & $\begin{array}{l}\text { Pascual Fortuño Marco } \\
\text { María Peset Gil y Vicente }\end{array}$ & 1 & 125 & 125 & Garrofa & Heretada & 1889 \\
\hline 16 & La Purificación* & 1901 & Vil & Cabedo Llopico & 1 & 150 & 150 & Garrofa & Heretada & 1885 \\
\hline 17 & El Porvenir & 1901 & Vil & Antonia Balaguer Vilar & 1 & 175 & 175 & Vinya & Heretada & 1887 \\
\hline 18 & San Antonio & 1901 & Vil & María Francisca Franch Perronat & 1 & 125 & 125 & Garrofa & Heretada & 1885 \\
\hline 19 & Unión Villarrealense & 1901 & Vil & & & & & & & \\
\hline 20 & sense nom $[R]^{*}$ & 1901 & Cas & & & & & & & \\
\hline 21 & San Marcos [R] & 1902 & Alm & Francisco Catalá Ballester & 1 & 200 & 200 & Garrofa & Heretada & \\
\hline 22 & Almazorcense & 1902 & Alm & & & & & & & \\
\hline 23 & Neptuno* & 1902 & Cas & Pascuala Escuder Cabedo & 1 & 50 & 50 & Garrofa & Donació & 1898 \\
\hline 24 & La Unión Hidráulica & 1902 & Cas & Salvador Usó Manrique & & 50 & 50 & Garrofa & & \\
\hline 25 & La Unión Hidráulica [R] & 1903 & Cas & & & & & & & \\
\hline 26 & Virgen de Gracia & 1904 & Vil & Manuel Lassala Emo & 1 & 250 & 250 & Garrofa & Comprada & 1904 \\
\hline 27 & Segura & 1904 & Vil & José Arrufat Rochera & 1 & 125 & 125 & Garrofa & Comprada & 1900 \\
\hline 28 & Virgen de Lourdes & 1904 & Vil & Catalino Moreno Canós & 1 & 125 & 125 & Garrofa & Comprada & 1904 \\
\hline 29 & Virgen del Carmen & 1905 & Vil & Pascual Bonet Bernat & 1 & 125 & 125 & Inculta & Rotulació & 1905 \\
\hline 30 & Corazón de Jesus & 1905 & Vil & Carmen Arrufat Avellana & 1 & 125 & 125 & Garrofa & Heretada & 1901 \\
\hline 31 & San Roque & 1905 & Vil & $\begin{array}{l}\text { Antonio Segura Gumabu } \\
M^{\circ} \text { de la Asunción Genoveva }\end{array}$ & 1 & 460 & 460 & Garrofa & Heretada & 1869 \\
\hline 32 & San Pedro & 1906 & Vil & Girona Garcáia & 1 & 175 & 175 & Garrofa & Heretada & \\
\hline 33 & La Fanguera & 1906 & Vil & Antonia Chabrera Molina & 1 & 150 & & Garrofa & Heretada & 1859 \\
\hline 34 & Unión Agrícola & 1906 & Vil & Vicenta Ayet Gil & 1 & 125 & 125 & Garrofa & Heretada & 1880 \\
\hline 35 & Balsa de Insa & 1906 & Vil & Domingo Gil Martín & 1 & 150 & 150 & Garrofa & Comprada & 1886 \\
\hline 36 & San Jaime & 1911 & Vil & Pascual Trual Ferrer & 1 & 125 & 125 & Figa/oliva & Heretada & 1882 \\
\hline 37 & La Bienvenida & 1911 & Vil & Vicente Fortuño Marco & 1 & 150 & 150 & & & \\
\hline 38 & San Benito & 1912 & Vil & Salvador Moner Petit & 1 & 60 & & Vinya & Divisió & 1901 \\
\hline 39 & San Miguel & 1912 & Vil & Vicenta Renau Gil & 1 & 100 & 100 & Inculta & Heretada & \\
\hline 40 & Cristo del Hospital & 1912 & Vil & Pascual Girona Gil & 1 & 125 & 125 & Garrofa & Heretada & 1887 \\
\hline 41 & La Magdalena & 1912 & Vil & José Remolar Torres & 50 & 67,50 & 135 & Garrofa & Donació & 1912 \\
\hline 42 & San Miguel [R] & 1912 & Vil & Juana Candau i Notari & 1 & 43 & 43 & Secà & Heretada & 1890 \\
\hline 43 & San Juan & 1912 & Vil & Bautista Usó Iserte & 1 & 125 & 125 & Garrofa & & \\
\hline 44 & Hidro-Agrícola & 1912 & Vil & Manuel Gurrea Marco & 1 & 75 & 75 & Garrofa & Comprada & 1912 \\
\hline 45 & Micha de la Tanda & 1912 & Bur & Pascual Falcó Font & 100 & 625 & 1250 & Hort & Heretada & 1910 \\
\hline 46 & La Igualdad & 1913 & Vil & Dolores Almela Ferrer & 90 & 217,50 & 150 & Vinya/oliva & Divisió & 1877 \\
\hline 47 & El Mijares & 1913 & Vil & Hermanos Peset Costa & 40 & 150 & 125 & & & \\
\hline 48 & Santa Quiteria & 1913 & Alm & Vicente Bono Gilabert & 1 & 150 & 150 & Garrofa & Comprada & 1913 \\
\hline 49 & San Gil & 1913 & Vil & Pascuala Viñez Gil & 1 & 50 & 50 & Secà & Heretada & \\
\hline 50 & San Vicente Ferrer* & 1913 & Vil & & 1 & 150 & 150 & Garrofa & Heretada & 1901 \\
\hline 51 & El Ebro & 1913 & Vil & Antonio de Brugada Peris & 1 & 200 & 200 & & & \\
\hline 52 & El Millars & 1914 & Vil & Pascual Vidal Escuer & 1 & 100 & 100 & Garrofa & Comprada & 1901 \\
\hline
\end{tabular}

51 Mida de la finca. La primera columna fa referència al nombre de fanecades i la segona al de braces.

52 Valor de la finca en pessetes.

53 Valor en pessetes d'una fanecada.

54 Cultiu anterior a la transformació.

55 Com va accedir l'antic propietari a la dita terra i a quin any. 


\section{DOCUMENTACIÓ ARXIVISTICA}

Escriptures procedents de l'Associació Comarcal de Pous de Reg, (A.C.P.R.). San Marcos, Almassora (1897): Godofredo Gimeno Alcoy, n492, 5-101897 (Vila-real). Comunidad de riego, venta y constitución de derechos de riego. Otorgada por José Chabrera Batalla y otros.

El Madrigal (1898a): Pedro Vicente y Monfort, n432, 11-12-1898 (Vila-real). Compra-venta. Otorgada por Marcelino Vicente y Gunea a Miguel Almela e Isach y otros.

El Madrigal (1898b): Pedro Vicente y Monfort, n433, 11-12-1898 (Vila-real). Convenio. Otorgada por Miguel Almela e Isach y otros.

Fomento Agrícola (1899): Godofredo Gimeno Alcoy, n572, 5-11-1899 (Vila-real). Sociedad civil particular, Otorgada por Antonio Soriano Gorriz y otros.

Agricultura Moderna (1899): Godofredo Gimeno Alcoy, n612, 28-11-1899 (Vila-real). Sociedad civil particular, Otorgada por Domingo Vicente Verdia Castelló y otros,

Camino Carretera (1899): Pedro Vicente y Monfort, n433, 31-12-1899 (Vila-real). Convenio. Otorgada por Vicente Beltran y Bellmunt y otros entre sí.

La Explotación Agrícola (1900): Godofredo Gimeno Alcoy, n43, 28-1-1900 (Vila-real). Sociedad civil particular y compra-venta, Otorgada por Pascual Cabedo Cantavella y otros.

Fomento de la Agrícola (1900): Godofredo Gimeno Alcoy, n¹20, 25-21900 (Vila-real). Sociedad civil particular y venta, Otorgada por Manuel Pesudo Gil y otros.

Progreso del Hortal (1900): Godofredo Gimeno Alcoy, n¹56, 10-3-1900 (Vila-real). Sociedad civil particular y venta, Otorgada por José Gallach Tallada, Plácido Fabra Adelantado y otros.

San Pascual (1900): Godofredo Gimeno Alcoy, n³38, 17-5-1900 (Vila-real). Sociedad civil y venta, Otorgada por Bárbara Petit Bosquet, Vicente Ssnchiz Almela y otros.

San Isidro (1900): Godofredo Gimeno Alcoy, n682, 4-11-1900 (Vila-real). Sociedad civil y venta, Otorgada por Ana María Pesudo Gil y otros.

El Pilar (1900): Pedro Vicente y Monfort, n539, 11-11-1900 (Vila-real). Convenio y cesión. Otorgada por José Dualde y otros.

El Porvenir (1901): Godofredo Gimeno Alcoy, n¹31, 5-3-1901 (Vila-real). Sociedad civil y venta,

El Pilar (1901): Pedro Vicente y Monfort, n84, 19-3-1901 (Vila-real). Convenio y cesión. Otorgada por Julián López Montins y otros. 
Virgen de Gracia (1904): Juan Bautista Nogues Sales, n409, 10-7-1904 (Vila-real). Convenio y venta.

Segura (1904): Godofredo Gimeno Alcoy, n640, 8-12-1904 (Vila-real). Sociedad civil y venta.

San Isidro (1905): Godofredo Gimeno Alcoy, n²90, 18-6-1905 (Vila-real). Sociedad civil particular, Otorgada por Joaquín Broch Fortuño y 51 más.

Corazón de Jesús (1905): Godofredo Gimeno Alcoy, n³49, 16-7-1905 (Vila-real). Sociedad civil y venta, Otorgada por Ana María Pesudo Gil y otros.

San Roque (1905): Godofredo Gimeno Alcoy, n500, 19-11-1905 (Vila-real). Sociedad civil y venta.

San Pedro (1905): Godofredo Gimeno Alcoy, n56, 4-2-1906 (Vila-real). Sociedad civil particular y compra-venta, Otorgada por María de la Asunción Genoveva Girona García, Pedro Broch Ortells y otros.

La Unión Agrícola (1906): Godofredo Gimeno Alcoy, n478, 4-11-1906 (Vila-real). Sociedad civil y venta, Otorgada por Vicenta Ayet Gil y otros.

San Jaime (1911): Juan Bautista Nogues Sales, n³66, 27-8-1911 (Vila-real). Sociedad común y venta. Otorgada por DFomingo Vicente Verdiá, Pascual Arnal Ferrer y otros.

La Bienvenida (1911): Juan Bautista Nogues Sales, n476, 8-12-1911 (Vila-real). Sociedad común y promesa de venta. Otorgada por Victoriano Fabra Pesudo y otros.

San Benito (1912): Godofredo Gimeno Alcoy, n²3, 14-1-1912 (Vila-real). Sociedad de riegos y compra-venta, Otorgada por Vicente Costa Ortiz y otros.

San Miguel (1912): Vicente Vilar Catala, n70, 28-1-1912 (Vila-real). Sociedad civil particular y conpra-venta. Otorgada por María Gracia Roca Gil y otros. Santísimo Cristo del Hospital (1912): Godofredo Gimeno Alcoy, n46, 28-11912 (Vila-real). Sociedad de riegos y compra-venta, Otorgada por Enrique Vínez Girona y otros.

San Miguel (1912): Vicente Vilar Catalá, n³39, 30-6-1912 (Vila-real). Reconstitución de sociedad civil o comunidad particular de regantes. Otorgada por María Gracia Roca Gil y otros.

San Juan (1912): Godofredo Gimeno Alcoy, n727, 22-12-1912 (Vila-real). Sociedad de riegos y compra-venta.

La Hidro Agrícola (1912): Juan Bautista Nogues Sales, n498, 22-12-1912 (Vila-real). Sociedad común y promesa de venta. Otorgada por Manuel Latorre y otros. 
Michà de la Tanda, Borriana (1912): Godofredo Gimeno Alcoy, n736, 261-1912 (Vila-real). Sociedad civil particular, Otorgada por Manuel Ramos Gumbau y otros.

Michà de la Tanda, Borriana (1913): Godofredo Gimeno Alcoy, n82, 2-21913 (Vila-real). Venta, Otorgada por Pascual Falcó Font a la sociedad.

La Igualdad (1913): Godofredo Gimeno Alcoy, n97, 9-2-1913 (Vila-real). Compra-venta y constitución de la sociedad civil particular.

El Mijares (1913): Godofredo Gimeno Alcoy, n¹23, 23-2-1913 (Vila-real). Sociedad civil particular o comunidad privada de regantes y compra-venta. Otorgada por Manuel Cantavella Albiol y otros.

Santa Quiteria, Almassora (1913): Andrés Gómez Begué, n75, 27-2-1913 (Almassora). Sociedad civil particular o comunidad privada de regantes y compra-venta. Otorgada por Vicente Pesudo Candau y otros.

San Gil (1913): Vicente Vilar Catalá, n¹06, 25-3-1913 (Vila-real). Sociedad civil y compra-venta. Otorgada por Manuel Cercós Martí y otros.

San Cristobal (1913): Godofredo Gimeno Alcoy, n²53, 10-5-1913 (Vila-real). Venta. Otorgada por Pascuala Ayet Pitarch.

El Ebro (1913a): Godofredo Gimeno Alcoy, n543, 6-11-1913 (Vila-real). Sociedad civil particular o comunidad privada de regantes.

El Ebro (1913b): Godofredo Gimeno Alcoy, n554, 18-11-1913 (Vila-real). Compra-venta. Otorgada por Antonio Brugada López.

El Millars (1914): Godofredo Gimeno Alcoy, n¹8, 11-1-1914 (Vila-real). Sociedad civil particular o comunidad privada de regantes y compra-venta. Otorgada por Francisco Ripollés Rochera y otros.

El Ebro (1914): Godofredo Gimeno Alcoy, n²6, 13-1-1914 (Vila-real). Venta. Otorgada por Pascual Vidal Escuder.

Escriptures procedents de l'Arxiu Històric Provincial de Castelló (A.H.P.).

Desconocida, Almassora (1900): Andrés Gómez Begué, n¹40, 15-5-1900 (Almassora). Cesión de tierra y constitución de sociedad.

La Nueva Riqueza Territorial (1901): Godofredo Gimeno Alcoy, n48, 7-11901 (Vila-real). Sociedad civil particular y venta. Otorgada por Pascual Fortuño Marco y otros.

El Sigle XX, Almassora (1901): Godofredo Gimeno Alcoy, n¹8, 13-1-1901 (Vila-real). Sociedad civil particular y venta. Otorgada por Manuel Esteller Jordá y otros.

La Purificación (1901): Godofredo Gimeno Alcoy, n65, 2-2-1901 (Vila-real). Sociedad civil particular y venta. Otorgada por Vicente Cabedo Llopico y otros. 
San Antonio (1901): Godofredo Gimeno Alcoy, n¹61, 17-3-1901 (Vila-real). Sociedad civil particular y compra-venta.

Desconocida, Castelló de la Plana (1901a): Andrés Gómez Begué, n¹59, 26-5-1901 (Almassora). Admisión de nuevos socios en una sociedad constituida para alumbrar aguas y emplearlas en el riego.

Desconocida, Castelló de la Plana (1901b): Andrés Gómez Begué, n³09, 27-12-1901 (Almassora). Cesión de tierra y constitución de sociedad.

Neptuno, Castelló de la Plana (1902a): Andrés Gómez Begué, n³19, 8-61902 (Almassora). Cesión de terreno, constitución de servidumbre y sociedad para riego.

San Marcos, Almassora (1902): Andrés Gómez Begué, n¹79, 14-9-1902 (Almassora). Sociedad para reflotar un pozo de agua potable.

Neptuno, Castelló de la Plana (1902b): Andrés Gómez Begué, n³69, 27. 10-1902 (Almassora). Disolución de la sociedad.

La Unión Hidráulica, Almassora (1902): Andrés Gómez Begué, n441, 8-121902 (Almassora). Constitución de la sociedad particular de riego y varias servidumbres.

La Unión Hidráulica, Almassora (1903): Andrés Gómez Begué, n¹0, 14 1-1903 (Almassora). Admisión de nuevos socios, compra-venta de tierra y una maquinaria y constitución de servidumbres de carretera

Arxiu Municipal de Vila-real (A.M.Vr.).

San Vicente Ferrer (1913): Societats de reg, altres pous, $n^{\circ} X X$. Godofredo Gimeno Alcoy, n²04, 6-4-1913 (Vila-real). Sociedad civil particular o comunidad privada de regantes y compra-venta. Otorgada por José Pesudo Mezquita y otros.

\section{REFERÈNCIES BIBLIOGRÀFIQUES}

Abad García, V. (1984): Historia de la naranja 1781-1939, València, Comité de Gestión de la Exportación de Frutos Cítricos.

BONO, E. (2010): Naranja y desarrollo, la base agrícola exportadora de la economía del País Valenciano y el modelo de crecimiento hacia afuera, Valencia, Universitat de València.

CAVANILLE, A. J. (1795): Observaciones sobre la historia natural, geografía, agricultura, población y frutos del Reyno de Valencia, Madrid, Imprenta Real. Domingo Pérez, C. (1983): La Plana de Castellón. Formación de un paisaje agrario mediterraneo, Castellón de la Plana, Caja de Ahorros y Monte de Piedad de Castellón.

Garrido Herrero, S. (2004): Canem gentil, l'evolució de les estructures agrà- 
ries a la Plana de Castelló (1750-1930), Castelló de la plana, Excelentísimo Ayuntamiento de Castellón de la Plana.

Garrido Herrero, S. (2010): "Les transformacions d'un model econòmic", en Historia de Vila-real. Vila-real, Ajuntament de Vila-real.

Membrado TenA, J. C. (1995): Vila-real, ciutat industrial: El taulell i les altres indústries en la història, el present $i$ el futur de la ciutat, Vila-real, II.Im. Ajuntament de Vila-real.

Obiol Menero, E. M. (1987): Toponimia rural de Vila-real, Caixa rural Vila-real.

Sarthou Carreres, C. (1914): Geografía general del Reino de Valencia. Provincia de Castellón, Barcelona, A. Martín.

Tomás CARpí, J. A. (1985): La lógica del desarrollo económico, el caso valenciano, València, Caja de Ahorros de València.

Traver Garcia, B. (1909): Historia de Villarreal, Vila-real, J. Botella. 